\title{
Examination of Rainfall-Induced Landslide Failure Mechanisms via a Centrifuge Physical Simulation Test
}

\author{
Shan Dong, Wenkai Feng, Yibo Yin, Rui Hu, Hongchuan Dai \\ State Key Laboratory of Geohazard Prevention and Geoenvironment Protection, Chengdu University of Technology, Chengdu, China \\ Email: dongshan1994@hotmail.com, fengwenkai@cdut.cn,799975514@qq.com,2509137194@qq.com,851977357@qq.com
}

How to cite this paper: Dong, S., Feng, W.K., Yin, Y.B., Hu, R. and Dai, H.C. (2019) Examination of Rainfall-Induced Landslide Failure Mechanisms via a Centrifuge Physical Simulation Test. Open Journal of Geology, 9, 1004-1021. https://doi.org/10.4236/ojg.2019.913102

Received: November 25, 2019 Accepted: December 24, 2019 Published: December 27, 2019

Copyright ( 2019 by author(s) and Scientific Research Publishing Inc. This work is licensed under the Creative Commons Attribution International License (CC BY 4.0).

http://creativecommons.org/licenses/by/4.0/

\begin{abstract}
Rainfall is one of the most important factors contributing to landslides, and gentle bedding incline, high-rainfall induced landslides are common throughout the world. Field observations and theoretical analyses have been used to assess slope instability caused by permeability variation. In this study, the influence of rainfall infiltration on gentle bedding incline slope behaviour was investigated using a centrifuge physical simulation test. The magnitude, pattern and development of pore water and earth pressure at the interface; the shear failure surface features; and the corresponding deformation and failure processes were considered. A model with interbedded sand and mud was created, and a centrifuge was used to simulate both natural and rainfall conditions. The weak intercalation was composed of single-material silty clay, and the landslide mass was composed of red-bed sandstone. A combination of photography, pore water pressure measurements and earth pressure measurements were used to examine the relationship between the pore water pressure, earth pressure and failure modes. When the slope experiences overall instability, the curves of the earth pressure and pore water pressure dramatically decrease. The results reveal that the failure shear surface largely depends on the differential creep caused by the properties of the rock mass and the rainfall infiltration.
\end{abstract}

\section{Keywords}

Rainfall-Induced Landslide, Centrifuge physical Simulation Test, Earth Pressure, Pore Water Pressure, Deformation and Failure Processes

\section{Introduction}

Landslides are common geological events around the world that often result in many casualties and large economic losses. China has one of the highest inci- 
dences of landslides globally. The economic losses caused by landslides in China amount to billions of dollars every year [1]. Among the different types of landslide triggers, rainfall, particularly in the context of rainstorms, is an important factor, and rainfall-induced landslides create significant hazards in many parts of the world, particularly in mountainous areas at the beginning of the rainy season [2]. Bedding-controlled landslides in alternating mudstone and sandstone beds on cataclinal slopes are common in China. They are characterized by gentle bed dip angles, and usually exhibit slow creep movements throughout the year. However, during the rainy season, they can have sudden accelerations and undergo large displacements [3]. For example, the Huashengdi landslide located in Yiliang County of Yunnan Province, China, was a rainfall-induced landslide that caused many casualties and considerable economic losses.

Rainfall-induced landslides often occur in soil slopes over shallow, impermeable bedrock due to a rise in the water table from rainfall, which accelerates the slope failure process [4] [5] [6]. The unit weight of the soil increases, and water pressure in the pores increases as the rainfall infiltrates, and both factors contribute to the occurrence of a landslide [7] [8]. Son Nguyen et al. used probabilistic analyses to assess the stability of unsaturated soil slopes exposed to rainfall [9]. G. Fausto et al. identified the rainfall conditions that triggered landslides using cumulative and continuous rainfall data, combined with detailed information regarding the time of the landslide occurrence [10]. F. Mario and B. Francesca proposed a modification of the conventional threshold model to assess the probability of rainfall-induced landslide reactivation [11]. D. N. Se'rgio et al. focused on pore water pressure generation in soils with different permeabilities and corresponding slope failure modes [12]. In existing landslides, heavy rainfall during the rainy season can trigger rapid acceleration, but slow creep displacements can be observed throughout the year [13]. Fan et al. [14] suggested that hydrostatic pressure can be responsible for landslide initiation, based on stability analyses and laboratory scale models. Although many studies have focused on rainfall-induced landslides, studies on the deformation and failure process of rainfall-induced landslides have mainly concentrated on soil landslides, as opposed to gentle bedding incline landslides, on which fewer studies have focused.

Physical modelling plays an important role in understanding landslide triggering mechanisms and is performed to validate theoretical and empirical assumptions [15]. The theories and concepts of centrifuge modelling have been described in various papers. This method has been widely used in geotechnical phenomena research [16] [17]. The concept of simulating rainfall in centrifuge slope model tests was introduced in the early 1990s considering the soil moisture content conservation [18]. Kimura et al. [19] performed centrifuge tests of slope models made of sandy loam to investigate the effect of heavy rain on their stability. Matziaris et al. [20] presented three series of centrifuge model tests on soil slopes to determine the rainfall characteristics that cause soil slope failure initiation with respect to soil properties and slope geometry. Although many studies have focused on this topic, the centrifuge simulation tests have mainly focused 
on soil landslides; few studies have attempted to simulate the deformation and failure processes of bedding rock landslides using centrifuge tests.

In this paper, the deformation and failure processes of smooth, gentle bedding incline rainfall-induced landslides are investigated using centrifuge physical simulation testing in both natural and rainfall conditions. In particular, this study focuses on the 1) magnitude, pattern and development of pore water and earth pressure at the interface; 2) the slope response in terms of the failure mode, including specific details, such as the exact location of the shear surface; and 3) the deformation and failure process of rainfall-induced landslides.

\section{Experimental Methods}

In this section, the similarity ratio is described first, followed by a description of the experimental material. Then, the experimental equipment and measurement devices are presented. The variable factors and experimental procedures are also discussed.

\subsection{Similarity Ratio}

Mathematically speaking, similarity refers to the fact that two figures have exactly the same shape, one of which can be transformed into another by zooming in, zooming out, panning or rotating. Rock and soil behaviour depends on its stress level and stress history, and the in-situ stress varies with depth; thus, these features must be replicated during centrifuge modelling. In the scaled physical model, gravity must be simulated by using a centrifugal machine if gravity cannot be neglected [21]. Compared to common solid mechanics problems, an additional independent variable, $\rho \boldsymbol{g}$, is considered in the slope displacement, stress and strain distribution functions. These physical quantity distributions are functions of the length, soil material properties, forces (including the body force and surface pressure), and coordinates.

$$
\begin{aligned}
& \boldsymbol{\omega}=f\left(l, l^{I}, l^{I I} \cdots ; E_{1}, v_{1}, E_{2}, v_{2} ; \boldsymbol{s}, \rho_{1} \boldsymbol{g}, \rho_{2} \boldsymbol{g}, \boldsymbol{w} ; \boldsymbol{d}\right) \\
& \boldsymbol{\sigma}=g\left(l, l^{I}, l^{I I} \cdots ; E_{1}, v_{1}, E_{2}, v_{2} ; s, \rho_{1} \boldsymbol{g}, \rho_{2} \boldsymbol{g}, \boldsymbol{w} ; \boldsymbol{d}\right) \\
& \boldsymbol{\varepsilon}=h\left(l, l^{I}, l^{I I} \cdots ; E_{1}, v_{1}, E_{2}, v_{2} ; \boldsymbol{s}, \rho_{1} \boldsymbol{g}, \rho_{2} \boldsymbol{g}, \boldsymbol{w} ; \boldsymbol{d}\right)
\end{aligned}
$$

where $\boldsymbol{\omega}$ is the deformation vector; $\boldsymbol{\sigma}$ is the stress tensor; $\boldsymbol{\varepsilon}$ is the strain tensor; $l$ is the geometry length used to characterize the geometry properties; $E_{1}$ and $E_{2}$ are the elastic moduli of the slope body and soil material of the sliding zone, respectively; $v_{1}$ and $v_{2}$ are the Poisson's ratios of the slope body and soil material of the sliding zone, respectively; $s$ is the surface pressure; $\rho_{1}$ and $\rho_{2}$ are the densities of the slope body and soil material of the sliding zone, respectively; $g$ is the gravitational acceleration; $\boldsymbol{w}$ is the constrained displacement vector; and $\boldsymbol{d}$ is the displacement vector.

Dimensionless functions of the displacements, stresses and strains are obtained using dimensional analysis. The component forms can be written as 


$$
\begin{aligned}
& \frac{\omega^{i}}{l}=f^{i}\left(\frac{l^{I}}{l}, \frac{l^{I I}}{l} \cdots ; v_{1}, \frac{E_{2}}{E_{1}}, v_{2} ; \frac{s}{E_{1}}, \frac{\rho_{1} g l}{E_{1}}, \frac{\rho_{2} g l}{E_{1}}, \frac{w}{l} ; \frac{x}{l}, \frac{y}{l}, \frac{z}{l}\right) \\
& \frac{\sigma^{i j}}{E_{1}}=g^{i j}\left(\frac{l^{I}}{l}, \frac{l^{I I}}{l} \cdots ; v_{1}, \frac{E_{2}}{E_{1}}, v_{2} ; \frac{s}{E_{1}}, \frac{\rho_{1} g l}{E_{1}}, \frac{\rho_{2} g l}{E_{1}}, \frac{w}{l} ; \frac{x}{l}, \frac{y}{l}, \frac{z}{l}\right) \\
& \varepsilon^{i j}=h^{i j}\left(\frac{l^{I}}{l}, \frac{l^{I I}}{l} \cdots ; v_{1}, \frac{E_{2}}{E_{1}}, v_{2} ; \frac{s}{E_{1}}, \frac{\rho_{1} g l}{E_{1}}, \frac{\rho_{2} g l}{E_{1}}, \frac{w}{l} ; \frac{x}{l}, \frac{y}{l}, \frac{z}{l}\right)
\end{aligned}
$$

Gravity can then be simulated using centripetal acceleration in the centrifugal model.

$$
\left(\frac{\rho_{1}\left(v^{2} / R\right) l}{E_{1}}\right)_{m}=\left(\frac{\rho_{1} g l}{E_{1}}\right)_{p}
$$

where subscript indices $m$ and $p$ represent the scaled centrifugal model and the prototype, respectively. $v$ is the rotation velocity, and $R$ is the rotation radius.

$$
\begin{aligned}
& \frac{\left(\rho_{1}\right)_{m}}{\left(\rho_{1}\right)_{p}} \cdot \frac{\left(v^{2} / R\right)_{m}}{(g)_{p}} \cdot \frac{\left(E_{1}\right)_{p}}{\left(E_{1}\right)_{m}}=\frac{(l)_{p}}{(l)_{m}}=N \\
& \frac{\left(\rho_{2}\right)_{m}}{\left(\rho_{2}\right)_{p}} \cdot \frac{\left(v^{2} / R\right)_{m}}{(g)_{p}} \cdot \frac{\left(E_{2}\right)_{p}}{\left(E_{2}\right)_{m}}=\frac{(l)_{p}}{(l)_{m}}=N
\end{aligned}
$$

One of the most common reasons for rainfall-triggered landslides is static liquefaction [22]. The internal mechanism of static liquefaction is an abrupt increase in pore pressure [23], which reduces the soil shear strength and leads to slope instability. Thus, when analysing rain-reduced landslides, the seepage force should be considered in a slope similarity analysis. The seepage velocity, seepage force and seepage time scaling laws are analysed in this section.

The seepage velocity is determined by Darcy's law:

$$
\begin{gathered}
u=k i=k \frac{\Delta h}{\Delta l} \\
\frac{(u)_{m}}{(u)_{p}}=\frac{(k)_{m}}{(k)_{p}} \cdot \frac{(\Delta h)_{m}}{(\Delta h)_{p}} \cdot \frac{(\Delta l)_{p}}{(\Delta l)_{m}}=\gamma_{m p}
\end{gathered}
$$

where $u$ is the seepage velocity, $k$ is the coefficient, $i$ is the hydraulic gradient, $\Delta h$ is the hydraulic head loss, $\Delta l$ is the seepage distance between particles in the microstructure, and $\gamma_{m p}$ is the ratio of the centripetal acceleration over the gravitational acceleration during the critical instability state.

For the seepage force:

$$
\begin{gathered}
\boldsymbol{J}=\rho_{w} g i \boldsymbol{e} \\
\left(\frac{\rho_{w}\left(v^{2} / R\right) i \Delta l}{E_{1}}\right)_{m}=\left(\frac{\rho_{w} g i \Delta l}{E_{1}}\right)_{p} \\
\frac{\left(\rho_{w}\right)_{m}}{\left(\rho_{w}\right)_{p}} \cdot \frac{\left(v^{2} / R\right)_{m}}{(g)_{p}} \cdot \frac{\left(E_{1}\right)_{p}}{\left(E_{1}\right)_{m}}=\frac{(i \Delta l)_{p}}{(i \Delta l)_{m}}=\frac{1}{\gamma_{m p}}
\end{gathered}
$$


where $J$ is the seepage force vector, $\rho_{w}$ is the density of water, and $\boldsymbol{e}$ is a unit vector in the seepage direction.

The seepage time can be obtained by the ratio of the length over the seepage velocity:

$$
\frac{(t)_{m}}{(t)_{p}}=\frac{(l)_{m}}{(l)_{p}} \cdot \frac{(u)_{p}}{(u)_{m}}=\frac{1}{N \gamma_{m p}} .
$$

In this research, the centrifuge slope model is based on a prototype model of the Huashengdi landslide located in Yiliang County of Yunnan Province, China, which was a rainfall-induced landslide. The landslide was approximately $780 \mathrm{~m}$ long east to west, with an average slope gradient of $15 \%$. The full landscape and landform of the landslide are shown in Figure 1. Bedrock in the Huashengdi landslide area is composed mainly of Middle Jurassic $\left(\mathrm{J}_{2} \mathrm{sn}\right)$ Shuining Formation (purple-red sandstone and sandy mudstone interbedded). The bedrock of the study area is composed of alternatively layered hard rock (sandstone) and soft rock (strongly weathered mudstone); the weak interlayer is formed of strong weathered mudstone under the action of water. All experiments are arranged in 15-degree slope layers, and divided into three layers: basement rock, a masonry slope with a stable and rough-cemented surface; weak intercalation, single-material silty clay; and the landslide mass, red-bed sandstone. In situ red-bed sandstone blocks and clay interlayer are used to simulate the layers, so the density and elasticity modulus similarity ratios of the landslide mass are equal to 1 , and the density and elasticity modulus similarity ratios of weak intercalation are 1.54 and 1.21, respectively. The length of the Huashengdi landslide was $780 \mathrm{~m}$, and the maximum acceleration in the centrifuge test is $150 \mathrm{~g}$. According to the formulas above, the detailed experimental similarity ratios are shown in Table 1.

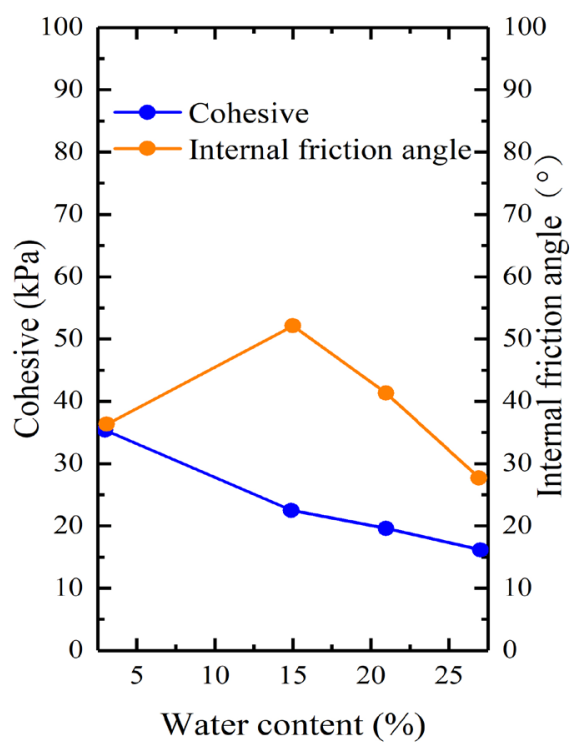

(a)

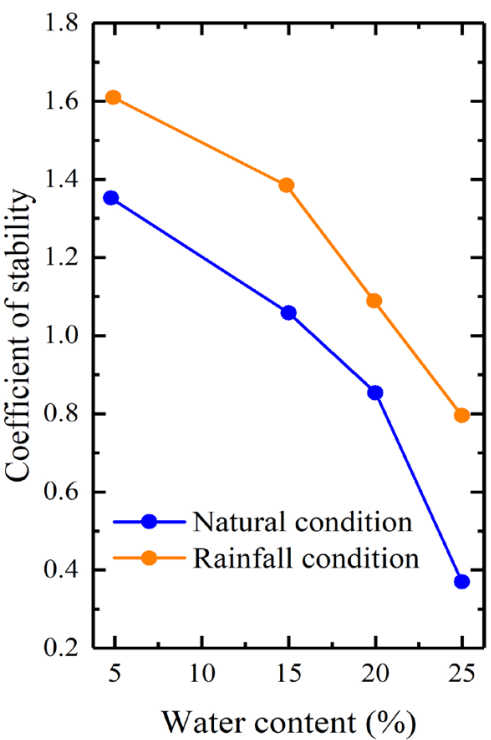

(b)

Figure 1. Relationships between the cohesive pressure, internal friction angle, coefficient of stability and moisture content. 
Table 1. Scaling parameters involved in this study (Where subscript indices $m$ and $p$ represent the scaled centrifugal model and the prototype, respectively).

\begin{tabular}{|c|c|}
\hline Parameter & Expression \\
\hline Characteristic geometry length of the slope & $\frac{(l)_{p}}{(l)_{m}}$ \\
\hline Density of the slope body & $\frac{\left(\rho_{1}\right)_{p}}{\left(\rho_{1}\right)_{m}}$ \\
\hline Density of the soil material of the sliding zone & $\frac{\left(\rho_{2}\right)_{p}}{\left(\rho_{2}\right)_{m}}$ \\
\hline Acceleration & $\frac{(g)_{p}}{\left(v^{2} / R\right)_{m}}$ \\
\hline Elastic modulus of the slope body & $\frac{\left(E_{1}\right)_{p}}{\left(E_{1}\right)_{m}}$ \\
\hline Elastic modulus of the soil material of the sliding zone & $\frac{\left(E_{2}\right)_{p}}{\left(E_{2}\right)_{m}}$ \\
\hline Seepage velocity & $\frac{(u)_{p}}{(u)_{m}}$ \\
\hline Seepage length of microstructure particles & $\frac{(\Delta l)_{p}}{(\Delta l)_{m}}$ \\
\hline Seepage time & $\frac{(t)_{p}}{(t)_{m}}$ \\
\hline
\end{tabular}

\subsection{Material}

The main factor affecting the mechanical properties of the weak intercalation is the moisture content; thus, the following considerations were adopted to determine the moisture content: 1 ) the $\mathrm{C}$ and $\varphi$ values were determined from direct shear tests and 2) the $\mathrm{C}$ and $\varphi$ values were input into GeoStudio for slope stability analysis. Four groups of experiments were performed to determine the moisture content (Figure 2), and the moisture content that was the most adverse to slope stability was chosen as the primary moisture content. In those tests, the material of the weak intercalation is clay and the direct shear tests are performed on samples compacted at dry and wet moisture contents $(\mathrm{w}=5 \%, 15 \%, 20 \%$ and $25 \%)$. The results indicate that the material's cohesive force of weak intercalation fluctuates with moisture content changes (within a certain range); When the moisture content is equal to $15 \%$, peak cohesion value is obtained, and the moisture content called optimum moisture content. On the dry side of the optimum moisture content ( $w=5 \%$ ), cohesion tends to decrease due to clay aggregation, which leads to soil granulation. The cohesion reduction on the wet side ( $\mathrm{w}=20 \%$ and $25 \%$ ) is caused by the formation of thicker water films around clay particles in the clay-water system [24]. The internal friction angle of the weak intercalation material decreases with increased moisture content (Figure 2). Below the optimum moisture content, when the clay is relatively dry $(\mathrm{w}=$ $5 \%$ ), matric suction produces a resistance to slippage at the contact points between the aggregates. However, the role of clay aggregates on the frictional 


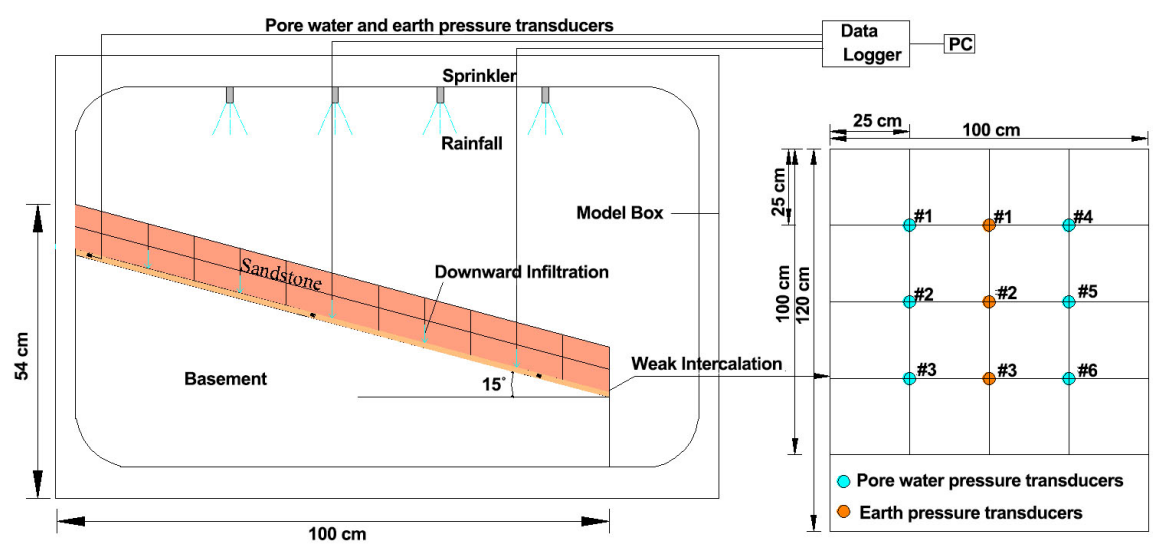

Figure 2. Experimental arrangement. Transducers were placed near the layers' surface contact (weak intercalation and sandstone) (left); diagram of the earth pressure and pore water pressure gauge positions (right).

behaviour of the clay is substantially reduced at approximately the optimum moisture content. The decrease in angle of friction with increasing moisture content ( $\mathrm{w}=20 \%$ and $25 \%)$ is attributed to decreasing suction values [25]. For the natural condition, the slope stability calculated by GeoStudio used finite element analysis to calculate the slope stress distribution, and the Mohr-Coulomb failure criterion is used to obtain the distribution of failure points and the plastic zone. Finally, the stability coefficient is obtained. The rainfall control condition is $250 \mathrm{~mm} / \mathrm{d}$; at this time, the rainfall intensity is greater than the permeability coefficient of the soil. Water flow occurs on the rock and soil surfaces, and the rainfall does not enter the soil completely. The boundary condition is the head boundary. Based on the numerical experimental results (Figure 1), when the moisture content in the weak intercalation is controlled at approximately 20 percent, the coefficient of stability in the natural condition is 1.12, and the slope is basically stable; in the rainfall condition, the coefficient of stability is less than 1 , and the slope is unstable.

According to the field investigation, there are two sets of dominant joints under the long-term geological process in the Huashengdi landslide. The occurrence of the first structural plane was $285^{\circ}-300^{\circ} \angle 70^{\circ}-80^{\circ}$, and the second was $183^{\circ}-195^{\circ} \angle 75^{\circ}-80^{\circ}$ (the two occurrences are nearly perpendicular, one is nearly horizontal, and the other is nearly perpendicular to the horizontal direction along the slope direction), while the length of the joint fissure was 10 - 60 $\mathrm{m}$. However, for the landslide mass, the small samples did not always represent the entire ground profile, and the existence of macrostructures, such as fissures and layering in the original sample, could not be scaled to the corresponding geometric size. There was a relatively large difference between the actual distribution of the stratum and the experimental one; According to the field investigation, the control structural planes were selected. In order to simulate joint fissures as much as possible, the red-bed sandstone was cut to simulate the control structural planes in the horizontal direction and the slope direction. 


\subsection{Equipment and Testing Procedure}

\subsubsection{Laboratory Experimental Equipment}

All of the tests were conducted using a TLJ-500 geotechnical centrifuge, the largest geotechnical centrifuge in China, at the State Key Laboratory of Geohazard Prevention and Geoenvironment Protection at the Chengdu University of Technology. Our experiments were conducted in a rectangular model box that was $1.2 \mathrm{~m}$ long, $0.8 \mathrm{~m}$ high and $1 \mathrm{~m}$ wide. However, only a portion of the box was used, as our models were typically $1 \mathrm{~m}$ long and $54 \mathrm{~cm}$ high (Figure 2 and Figure 3 ). The lateral sides were made of glass to allow the slope failure process to be observed.

An artificial rainfall simulator composed of a metallic porous plate and multiple nozzles were placed at the top of the model box, from which water infiltrated for the experiments via downward infiltration (Figure 2(b)). Three earth pressure and six pore water pressure transducers $(8 \mathrm{~mm}$ in diameter, with a range of $0.5 \mathrm{MPa}$, an accuracy of $1 \% \mathrm{FS}$, a 6 - 12 VDC power supply, a 0 - 2 VDC output voltage, an allowable overload of $120 \% \mathrm{FS}$, and a temperature range of $0^{\circ} \mathrm{C}$ $45^{\circ} \mathrm{C}$ ) produced by the Institute of Systems Engineering, part of the Chinese Academy of Engineering Physics were inserted at the desired locations in the weak intercalation. A site plan for the sensors is shown in Figure 2. To minimize the interference between the sensors, we set them at a distance of no less than 6 times their radius from each other. Furthermore, to ensure that the pore water pressure was measured correctly, the space between the head of the transducer and cap was filled with water to avoid entrapping air bubbles. The transducers were calibrated before each test by submerging them in a tank of water at a depth of $10 \mathrm{~cm}$ and recording the corresponding values. In every test, the positive pore water pressure and earth pressure were recorded, and the failure mode was observed by photographs with a high-speed video camera (Figure 3(a) and Figure 3(b)).

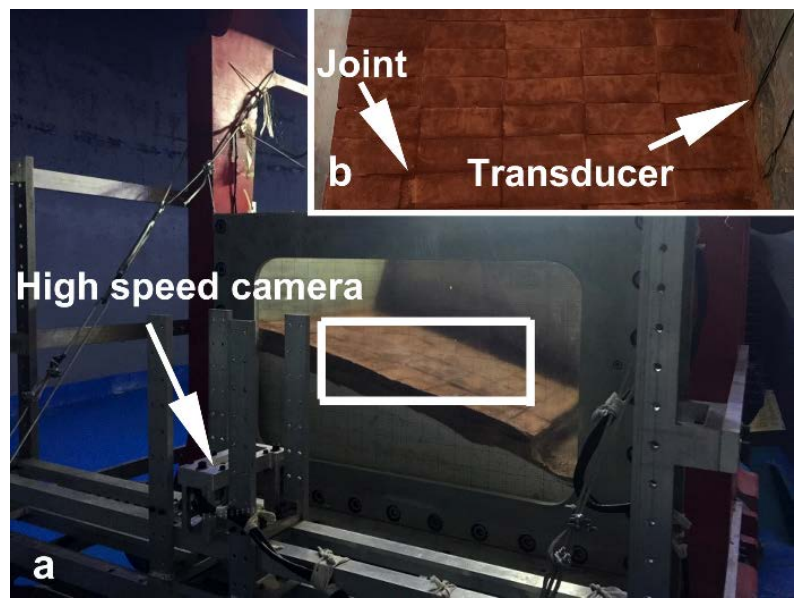

Figure 3. (a) Slope model and high-speed video camera; (b) Distribution of the joints and local enlarged drawing of the model. 


\subsubsection{Experimental Procedure}

Before the experiment, the model was weighed to calculate the centre of gravity for the centrifuge counterweight. Then, the experiments were performed under two conditions: natural and rainfall. In the rainfall condition, the water infiltrated from the top of the upper layer via artificial rainfall. During the testing process, considering the bearing capacity and safety factors of the centrifuge, the centrifugal acceleration was loaded step-by-step to avoid breaking the centrifuge under the action of inertia. The experimental procedure steps can be summarized as follows:

1) The centrifugal acceleration increased from $0 \mathrm{~g}$ to $20 \mathrm{~g}$, the rock and soil mass was tightly compacted, and the man-made inhomogeneity during the model-making process was adjusted.

2) After the rock and soil mass became tightly compacted, the acceleration was increased to $50 \mathrm{~g}$. After the centrifuge reached a stable state, the acceleration was increased to $100 \mathrm{~g}$, during which any settlement cracks were observed.

3) The acceleration was then increased from $100 \mathrm{~g}$ to $120 \mathrm{~g}$. For the rainfall condition, the first artificial rainfall was performed with the rainfall infiltrating from the top of the upper layer to the weak intercalation.

4) The acceleration was then increased from $120 \mathrm{~g}$ to $140 \mathrm{~g}$. For the rainfall condition, the soil of the weak intercalation was softened.

5) The acceleration was increased to $150 \mathrm{~g}$, and a uniform rotation was maintained until the slope failed. For the rainfall condition, there was continuous rainfall before and during landslides.

6) The high-speed video camera recorded the failure process.

\section{Results and Deformation and Failure Process}

\subsection{Results}

For convenience, the results are analysed in both the natural operating condition and the rainfall condition, with each condition maintaining the same layer position and infiltration direction. In this study, failure is defined when slope deformation is observed by the unaided eye. Under natural conditions, the slope exhibited a small tensile crack parallel to the alignment of the landslide, which created ladder-type damage; however, there was no clear downward offset (Figure 4(a) and Figure 4(b)). However, for the rainfall conditions, the slides occur within a short period of time, and the tensile fractures at the rear of the slope body are obvious (Figure 5(b)). In addition, the sandstone in the lower layer largely breaks off (Figure 4(c) and Figure 4(d)).

\subsection{Deformation and Failure Process}

This section describes the deformation and failure process of the landslide model in the rainfall condition. The experimental process illustrates that the slope first experienced consolidation and sedimentation before tensile cracks appeared at the trailing edge. These tensile cracks developed inward as the slope deformation 

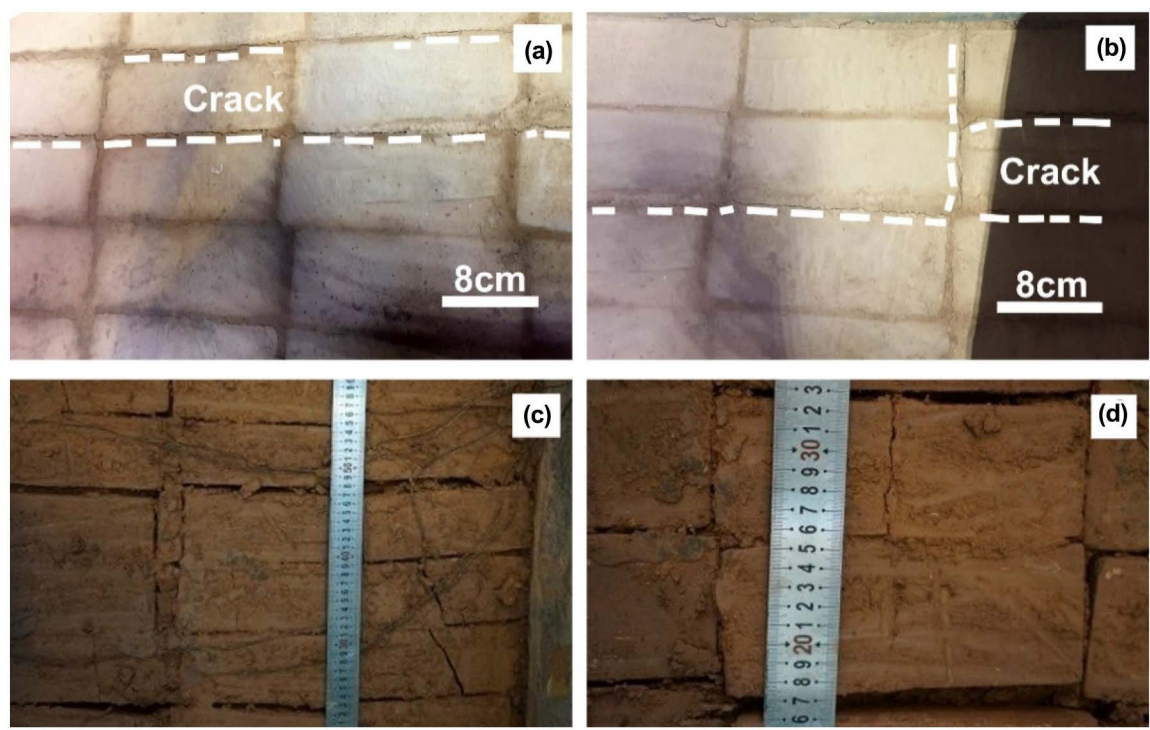

Figure 4. (a) The small cracks are on the trailing edge of the right sides in the natural operating condition; (b) The ladder-type damage is on the trailing edge of the left sides in the natural operating condition; (c) and (d) Fractured sandstone in the contact surface area of the weak intercalated layer and sandstone.
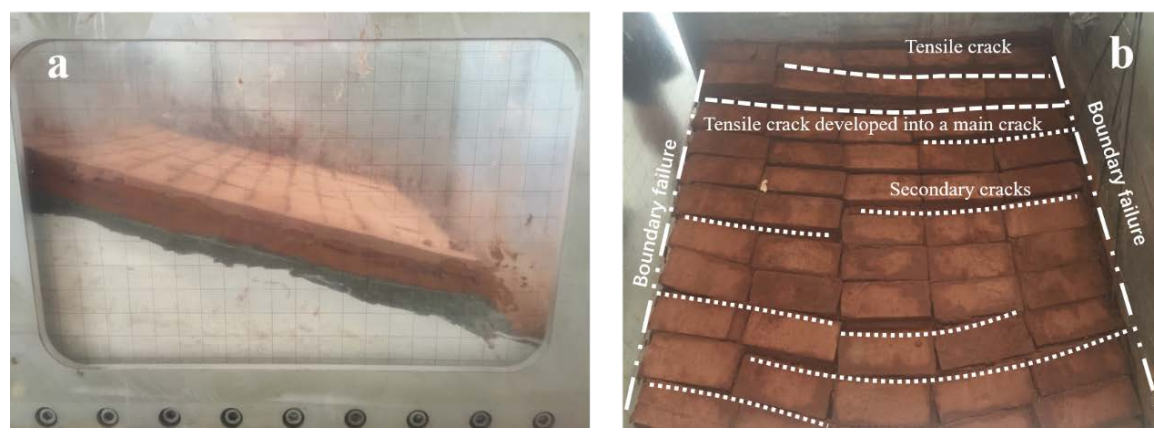

Figure 5. (a) The model before the centrifuge test; (b) The model after the rainfall condition centrifuge test, showing the overall slope instability that emerged.

increased, and the slope gradually became completely unstable. The deformation and failure process can be divided into the following stages based on experimental records provided by the high-speed camera and post-analysis:

1) Overall sedimentation. The rock and soil mass were tightly compacted in this stage, and the man-made inhomogeneity (created during the model-making process) was adjusted (Figure 6(a)).

2) Tensile crack formation at the trailing edge. A tensile crack appeared at the trailing edge due to the centrifugal force, and then rapidly expanded. Tensile crack penetration occurred at the top of the slope, and as the width of the tensile crack increased, the tensile crack developed into a main crack (Figure 6(b) and Figure 6(c)).

3) Development of secondary cracks at the leading edge. With increased centrifugal acceleration, the tensile crack at the trailing edge continued to propagate 

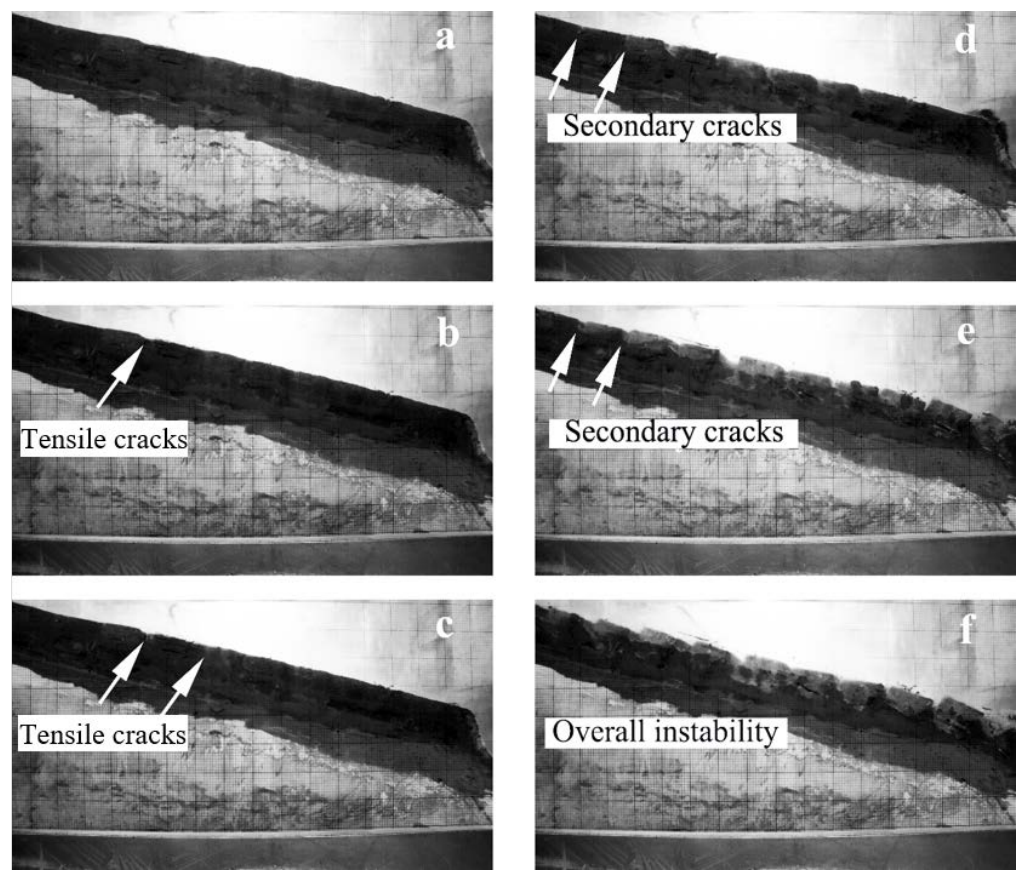

Figure 6. (a) The man-made inhomogeneity was adjusted. (b) and (c) Tensile cracks at the trailing edge: development, expansion, and penetration; (d) Secondary cracks at the leading-edge development stage; (e) Stage of shearing out in the front edge, secondary extension crack development at the trailing edge, and shear failure development; (f) Overall instability stage.

and an extrusion front, secondary crack developed toward the leading edge of the slope (Figure 6(d)), and the sandstone in the lower layer formed shear cracks at the same time.

4) Shearing out in the front edge, development of secondary extension cracks at the trailing edge, and shear failure development. With increasing deformation, the slope continued to deform in the direction of open space (Figure 6(e)).

5) Overall instability stage. After the extensive development of secondary cracks and shearing out in the front edge, total shear failure began to develop, and the overall instability of the slope emerged. After this, the sliding process finished within a short period of time (Figure 6(f)).

\section{Discussion}

The main objective of our experiment was to examine the deformation and failure processes of smooth, gentle bedding incline, rainfall-induced landslides, particularly focusing on the magnitude, pattern and development of the pore water and earth pressure at the interface, and the slope response in terms of failure mode, including specific details, such as the exact location of the shear surface.

\subsection{Earth Pressure and Pore Water Pressure}

\subsubsection{Natural Condition}

The earth pressure consistently increased with increases in the centrifugal accel- 
eration during the centrifugal loading. This increasing trend of measured values at gauge \# 3 was greater than the trend at gauge \#2, and the trend at gauge \#2 was also greater than that at gauge \#1 (Figure 7(a)). This result illustrates that the landslide thrust was continuously extruding toward the leading edge, which induced an increase in the value of the earth pressure measured at the leading edge.

Deformation and cracks will contribute to pore water runoff, so if deformation or cracks occurred in the slope, the pore water pressure will obviously decrease. The measured pore water pressure at gauge \#1, located on the left side of the trailing edge of the landslide, fluctuated considerably, indicating that there was continuous sedimentation or deformation. Following the test, we observed a small crack near the left side of the trailing edge of the landslide body, which was the most obvious one of the entire experiment. However, because this crack was located near the border, the fluctuation of the curve may also be related to border effects. The pore water pressure increased with increasing centrifugal acceleration during centrifugal loading at $\# 2$ and $\# 4$, but it began to decrease after the centrifugal acceleration reached $150 \mathrm{~g}$. The pressures at \#3, \#6 and \#5 reveal that the slope deformed locally (Figure $7(\mathrm{~b})$ and Figure $7(\mathrm{c})$ ) because deformation leads to water loss and a pore water pressure decrease.

\subsubsection{Rainfall Conditions}

In the course of this test, the relationship between the earth pressure and the centrifugal acceleration was measured, as shown in Figure 7(d). The measured values of the earth pressure increased continuously with increases in the centrifugal acceleration during centrifugal loading. For the water pressure, no significant decreasing trend appears in the curves, and the pore water pressure continues to increase with the rainfall (Figure $7(\mathrm{e})$ and Figure $7(\mathrm{f})$ ). The earth pressure and pore water pressure curves experienced a sudden decrease at $\mathrm{t}=$ $2680 \mathrm{~s}$. Compared with the trend in the pore water pressure curves with time in the natural operating condition model, this shows that the permeation of rainfall into the landslide area increased the water pressure in the cracks.

\subsection{Failure Mechanisms}

Direct shear tests on the weak interlayer were carried out to see the difference after the centrifuge test. Four identical soil samples are taken to test the shear stress when shear failure occurs under different vertical pressures. The least square method is used to minimize the sum of squares of deviations between points and straight lines, and the equation of fitting straight lines, friction angle and cohesion are determined accordingly. Figure 8 shows the results of the direct shear test of the weak interlayer in unsaturated and saturated conditions before and after the centrifuge test. Before the centrifuge test and after the natural condition centrifuge test, the cohesion and internal friction angle of the unsaturated weak interlayer are $c=40.16 \mathrm{kPa}, \varphi=20^{\circ}$ and $c=30.2 \mathrm{kPa}, \varphi=17.5^{\circ}$, respectively. For the saturated weak interlayer after the rainfall condition 

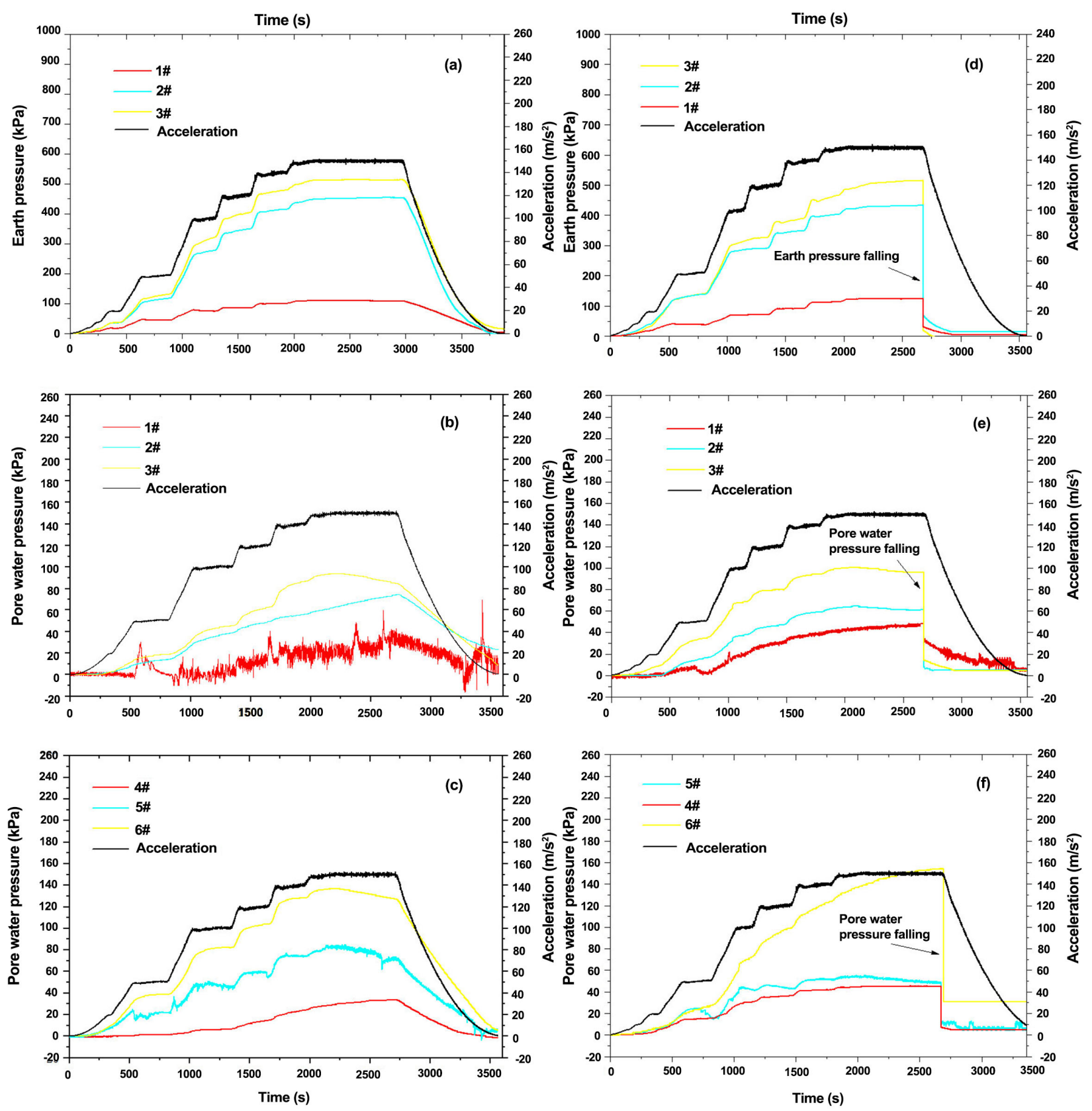

Figure 7. (a) Earth pressure curves vs. time in the natural operating condition model; (b) and (c) Pore water pressure curves with time in the natural operating condition model; (d) Earth pressure curves with time in the rainfall condition model; (e) and (f) Pore water pressure curves with time in the rainfall condition model.

centrifuge test, the cohesion and internal friction angle of the unsaturated weak interlayer are $\mathrm{c}=15.4 \mathrm{kPa}$ and $\varphi=14^{\circ}$.

Comparing the results, a marked difference is observed between the values measured in the direct shear tests. The results show that the soil strength not only decreased in the rainfall condition but also decreased in the natural condition. The unsaturated soils are becoming saturated due to rainfall infiltration, and the shear strength is weakened because matric suction decreases. However, the strength of unsaturated soil (after the centrifuge test) was also smaller than 


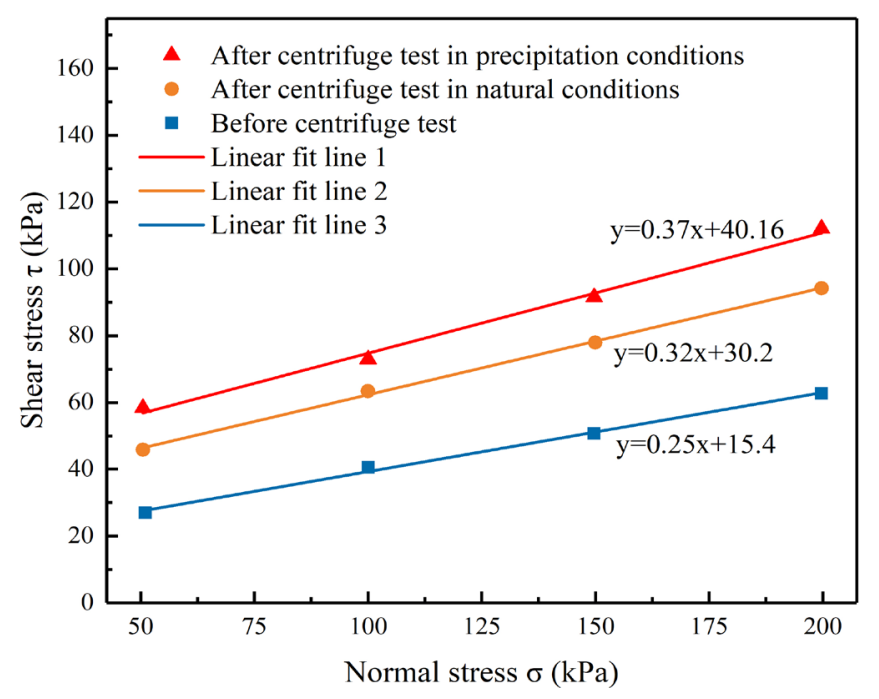

Figure 8. The relationship between the normal stress and shear stress.

that was not experienced the centrifuge test. What's more, after the experiment, there is no breaking off in the surface sandstone, whereas the sandstone in the lower layer largely breaks off. Thus, the squeeze damage mainly occurred in the contact surface area of the weak intercalated layer and sandstone (Figure 4(c) and Figure 4(d)). The interesting phenomenon reflects that a slow creep process happened in the slope with the soil strength decrease, which led to the small tensile cracks that developed, but the slope remained basically stable. With rainfall penetration, the slope creep increased, and the small cracks also developed further. Finally, the persistent rain will trigger the deformation of the slope's rapid acceleration in a short time, and the overall slope slid suddenly. Extensive plastic deformation occurs in the weak intercalated layer because silty clay is a low-intensity soft rock, and it softens when exposed to water. In contrast, sandstone exhibits significant brittle deformation because it is a hard rock with high strength. Under the effect of centrifugal force, high-dip joints formed in the thick sandstone layer due to differential creep. Head pressure was generated when the surface water infiltrated down along the joints, which produced a dilatancy effect and accelerated the differential deformation of the weak intercalated layer, sandstone and extension of high-dip joints, giving rise to early slope crack formation. The weak intercalated layer generated a stress concentration under the centrifugal force, forming an interlayer shear zone, and as a result, the structural connection was broken as joint fissures developed. Then, the artificial rainfall continued after $150 \mathrm{~g}$, and the rainfall infiltration caused already-shattered sandstone blocks to fracture further under the effect of fissure water pressure, and the sliding force also increased in saturated conditions. Additionally, the weak intercalated layer continued to soften in water, resulting in further strength decreases.

\section{Conclusions}

Gentle bedding incline, rainfall-induced landslide deformation and failure proc- 
esses and mechanisms were examined via a centrifuge physical simulation test. For weak interlayer soil, the reduction of the cohesion on the wet side of optimum moisture content is attributed to the formation of thicker water films around clay particles in the clay-water system. Whereas the internal friction angle of the weak interlayer soil decreased with increases in the moisture content. Below the optimum moisture content, the clay is relatively dry, and matric suction seems to generate a resistance to slippage at the contacts between the aggregates. However, the role of clay aggregates on the frictional behaviour of the clay is substantially reduced at approximately the optimum moisture content.

The deformation and failure processes of the landslide model were divided into five stages: 1) overall sedimentation; 2) tensile crack formation at the trailing edge; 3) development of secondary cracks at the leading edge; 4) shearing out in the front edge; and 5) overall instability.

A tensile crack appeared at the trailing edge due to the centrifugal force and then rapidly expanded. Tensile crack penetration occurred at the top of the slope, and as the width of the tensile crack increased, the tensile crack developed into a main crack. Except for the overall instability of the slope, the sandstone in the lower layer largely breaks off. The failure shear surface largely depends on the differential creep caused by the properties of the rock mass and the rainfall infiltration. An initial stage of slow sliding occurs. The landslide was induced by permeation of rainfall, which generated an unbalanced sliding force and decreased the shear resistance of the sliding zone soil. Early rainfall infiltration followed by a subsequent heavy rainfall is necessary to initiate landslides in gently inclined beds.

\section{Acknowledgements}

This project was supported by the Sichuan Provincial Youth Science and Technology Innovation Team Special Projects of China (Grant Number: 2017TD0018), the National Natural Science Foundation of China (Grant Number: 41572291), the Team Project of Independent Research of SKLGP (Grant No. SKLGP2016Z001), and the Open Fund of SKLGP (Grant No. SKLGP2019K010), and the Geohazards Investigation in the Town and Village Areas Located in the Northern Part of the Wumeng Mountain Area (DD20160274).

\section{Data Availability Statement}

This paper used by the relevant data, each did not indicate the source of, all from the experiment. The all data used to support the findings of this study are available from the corresponding author upon request.

\section{Conflicts of Interest}

The authors declare no conflicts of interest regarding the publication of this paper. 


\section{References}

[1] Wang, S. (2003) Century Achievements and New Historical Mission of Rock Mechanics and Engineering in China. Chinese Journal of Rock Mechanics \& Engineering, 2, 867-871.

[2] Wang, G. and Sassa, K. (2003) Pore-Pressure Generation and Movement of Rainfall-Induced Landslides: Effects of Grain Size and Fine-Particle Content. Engineering Geology, 69, 109-125. https://doi.org/10.1016/S0013-7952(02)00268-5

[3] Hu, W., Scaringi, G., Xu, Q., Asch, T.W.J.V., Huang, R. and Han, W. (2018) Suction and Rate-Dependent Behaviour of a Shear-Zone Soil from a Landslide in a Gently-Inclined Mudstone-Sandstone Sequence in the Sichuan Basin, China. Engineering Geology, 237, 1-11. https://doi.org/10.1016/j.enggeo.2018.02.005

[4] Cho, S.E. (2009) Infiltration Analysis to Evaluate the Surficial Stability of Two-Layered Slopes Considering Rainfall Characteristics. Engineering Geology, 105, 32-43. https://doi.org/10.1016/j.enggeo.2008.12.007

[5] Han, T.C., Dou, H.Q., Gong, X.N., Zhang, J. and Ma, S.G. (2014) A Rainwater Redistribution Model to Evaluate Two-Layered Slope Stability after a Rainfall Event. Environmental \& Engineering Geoscience, 20, 163-176. https://doi.org/10.2113/gseegeosci.20.2.163

[6] Ng, C.W.W. and Shi, Q. (1998) A Numerical Investigation of the Stability of Unsaturated Soil Slopes Subjected to Transient Seepage. Computers \& Geotechnics, 22, 1-28. https://doi.org/10.1016/S0266-352X(97)00036-0

[7] Ng, C.W.W. and Shi, Q. (1998) Influence of Rainfall Intensity and Duration on Slope Stability in Unsaturated Soils. Quarterly Journal of Engineering Geology Hydrogeology, 31, 105-113. https://doi.org/10.1144/GSL.QJEG.1998.031.P2.04

[8] Rahardjo, H., Ong, T.H., Rezaur, R.B. and Leong, E.C. (2007) Factors Controlling Instability of Homogeneous Soil Slopes under Rainfall. Journal of Geotechnical \& Geoenvironmental Engineering, 133, 1532-1543. https://doi.org/10.1061/(ASCE)1090-0241(2007)133:12(1532)

[9] Nguyen, T.S., Likitlersuang, S., Ohtsu, H. and Kitaoka, T. (2017) Influence of the Spatial Variability of Shear Strength Parameters on Rainfall Induced Landslides: A Case Study of Sandstone Slope in Japan. Arabian Journal of Geosciences, 10, 369. https://doi.org/10.1007/s12517-017-3158-y

[10] Guzzetti, F., Cardinali, M., Reichenbach, P., Cipolla, F., Sebastiani, C., Galli, M. and Salvati, P. (2004) Landslides Triggered by the 23 November 2000 Rainfall Event in the Imperia Province, Western Liguria, Italy. Engineering Geology, 73, 229-245. https://doi.org/10.1016/j.enggeo.2004.01.006

[11] Floris, M. and Bozzano, F. (2008) Evaluation of Landslide Reactivation: A Modified Rainfall Threshold Model Based on Historical Records of Rainfall and Landslides. Geomorphology, 94, 40-57. https://doi.org/10.1016/j.geomorph.2007.04.009

[12] Lourenço, S.D.N., Sassa, K. and Fukuoka, H. (2006) Failure Process and Hydrologic Response of a Two Layer Physical Model: Implications for Rainfall-Induced Landslides. Geomorphology, 73, 115-130. https://doi.org/10.1016/j.geomorph.2005.06.004

[13] Xu, Q., Liu, H., Ran, J., Li, W. and Sun, X. (2016) Field Monitoring of Groundwater Responses to Heavy Rainfalls and the Early Warning of the Kualiangzi Landslide in Sichuan Basin, Southwestern China. Landslides, 13, 1-16. https://doi.org/10.1007/s10346-016-0717-3

[14] Fan, X.M., Xu, Q., Zhang, Z.Y., Meng, D.S. and Tang, R. (2009) The Genetic Mechanism of a Translational Landslide. Bulletin of Engineering Geology and the En- 
vironment, 68, 231-244. https://doi.org/10.1007/s10064-009-0194-1

[15] Wood, D.M. (2004) Geotechnical Modelling. Spon Press, London. https://doi.org/10.4324/9780203477977

[16] Schofield, A.N. (1980) Cambridge Geotechnical Centrifuge Operations. Geotechnique, 30, 227-268. https://doi.org/10.1680/geot.1980.30.3.227

[17] Taylor, R.N. (1995) Geotechnical Centrifuge Technology. Blackie Academic \& Professional, CRC Press.

[18] Knodel, P.C., Craig, W.H., Bujang, B. and Merrifield, C.M. (1991) Simulation of Climatic Conditions in Centrifuge Model Tests. Geotechnical Testing Journal, 14, 7. https://doi.org/10.1520/GTJ10209J

[19] Kimura, T., Takemura, J., Suemasa, N., et al. (1991) Failure of Fills Due to Rain Fall. Proceedings of the International Conference, Vol. 91, 509-518.

[20] Matziaris, V., Marshall, A.M. and Yu, H.S. (2015) Centrifuge Model Tests of Rainfall-Induced Landslides. Springer International Publishing, Berlin. https://doi.org/10.1007/978-3-319-11053-0_7

[21] Tan, Q.M. (2011) Dimensional Analysis. With Case Studies in Mechanics. Springer, Berlin Heidelberg.

[22] Askarinejad, A., Laue, J., Zweidler, A., Iten, M., Bleiker, E., Buschor, H. and Springman, S.M. (2012) Physical Modelling of Rainfall Induced Landslides under Controlled Climatic Conditions. Eurofuge, Delft, 23-24 April 2012.

[23] Take, W.A., Bolton, M.D., Wong, P.C.P. and Yeung, F.J. (2004) Evaluation of Landslide Triggering Mechanisms in Model Fill Slopes. Landslides, 1, 173-184. https://doi.org/10.1007/s10346-004-0025-1

[24] Seed, H.B., Mitchell, J.K. and Chan, C.K. (1961) The Strength of Compacted Cohesive Soils. In: Shear Strength of Cohesive Soils, ASCE, Boulder, 877-964.

[25] Cokca, E., Erol, O. and Armangil, F. (2004) Effects of Compaction Moisture Content on the Shear Strength of an Unsaturated Clay. Geotechnical and Geological Engineering, 22, 285-297. https://doi.org/10.1023/B:GEGE.0000018349.40866.3e 


\section{List of Symbols}

\begin{tabular}{|c|c|c|}
\hline Parameter & Symbol & Dimension \\
\hline Deformation vector & $\omega$ & $\mathrm{L}$ \\
\hline Stress tensor & $\sigma$ & $\mathrm{ML}^{-1} \mathrm{~T}^{-2}$ \\
\hline Strain tensor & $\varepsilon$ & 1 \\
\hline Gravitational acceleration & g & $\mathrm{LT}^{-2}$ \\
\hline Seepage force & $\mathrm{J}$ & $\mathrm{ML}^{-2} \mathrm{~T}^{-2}$ \\
\hline Surface pressure & s & $\mathrm{ML}^{-1} \mathrm{~T}^{-2}$ \\
\hline Constrained displacement vector & $\mathbf{w}$ & $\mathrm{L}$ \\
\hline Displacement vector & d & $\mathrm{L}$ \\
\hline Unit vector of the seepage direction & e & 1 \\
\hline Geometry length & 1 & $\mathrm{~L}$ \\
\hline Rotation radius & $R$ & $\mathrm{~L}$ \\
\hline Hydraulic head loss & $\Delta h$ & $\mathrm{~L}$ \\
\hline Seepage distance in the microstructure between particles & $\Delta l$ & $\mathrm{~L}$ \\
\hline Rotation velocity & v & $\mathrm{LT}^{-1}$ \\
\hline Seepage velocity & $u$ & $\mathrm{LT}^{-1}$ \\
\hline Seepage coefficient & $k$ & 1 \\
\hline Hydraulic gradient & $i$ & 1 \\
\hline Seepage time & $t$ & $\mathrm{~T}$ \\
\hline Ratio of centripetal acceleration over gravitational acceleration & $\gamma_{m p}$ & 1 \\
\hline Elastic modulus of the slope body & $E_{1}$ & $\mathrm{ML}^{-1} \mathrm{~T}^{-2}$ \\
\hline Elastic modulus of the sliding zone & $E_{2}$ & $\mathrm{ML}^{-1} \mathrm{~T}^{-2}$ \\
\hline Poisson's ratio of the slope body & $v_{1}$ & 1 \\
\hline Poisson's ratio of the sliding zone & $v_{2}$ & 1 \\
\hline Density of the slope body & $\rho_{1}$ & $\mathrm{ML}^{-3}$ \\
\hline Density of the sliding zone & $\rho_{2}$ & $\mathrm{ML}^{-3}$ \\
\hline Density of water & $\rho_{W}$ & $\mathrm{ML}^{-3}$ \\
\hline
\end{tabular}

